\title{
Surgical management of progression to type A dissection from an intramural hematoma previously treated with endovascular stent graft placement
}

Carlo Savini, MD, ${ }^{*}$ Filip Casselman, MD, PhD, Mehmet U. Ergenoglu, MD, Ivan Degrieck, MD, Franck Van Praet, MD, Raphael De Geest, MD, Francis Wellens, MD, Hugues Jeanmart, MD, and Hugo Vanermen, MD, Aalst, Belgium

$\mathrm{T}$ he best management of intramural hematoma of the aorta (IMH) is still controversial. There is increasing evidence in the literature ${ }^{1,2}$ to justify the same approach as that used in classic aortic dissection.

We report a case of a patient in whom an IMH, which involved the ascending aorta, the arch, and the descending thoracic aorta, initially progressed to type B and, 1 month later, to type A aortic dissection.

\section{Clinical Summary}

A 58-year-old man with a history of hypertension was admitted for posterior chest pain. Chest computed tomographic (CT) scanning (Figure 1, A) revealed an IMH in the ascending aorta, the arch, and the proximal descending aorta. Because the patient was hemodynamically stable, conservative antihypertensive treatment was instituted. Several days later, persistent pain urged a new CT scan, which showed a tear-like lesion in the proximal descending thoracic aorta (Figure 1, B) for which an endovascular stent graft (Talent $34 \mathrm{~mm}$, Medtronic AVE) was inserted (by ID). The immediate result was satisfactory, and the patient was discharged a few days later. Four weeks after the endovascular treatment, the patient presented again with chest pain, and a new CT scan (Figure 1,C) showed a classic type A dissection. The patient was operated on urgently (by F.C.) through a median sternotomy, and cardiopulmonary bypass was instituted with bicaval cannulation for venous return; an echocardiography-guided femoral venous cannula (21F, DLP, Medtronic Inc) was inserted in the right femoral artery and advanced into the stent graft to have a partial antegrade flow starting from the proximal descending thoracic aorta. The internal inspection of the arch showed a disruption of each supraaortic vessel from the arch; in addition, the left subclavian artery was partially covered by the free bars of the stent graft.

From the Department of Cardiovascular and Thoracic Surgery, Onze Lieve Vrouw Ziekenhuis, Aalst, Belgium.

*Dr Savini is currently affiliated with the Department of Cardiovascular Surgery, Ospedale S.Orsola-Malpighi, University of Bologna, Italy

Received for publication April 28, 2004; revision received May 13, 2004; accepted for publication May 21, 2004.

Address for reprints: Filip Casselman, MD, PhD, Department of Cardiovascular and Thoracic Surgery, O.L.V. Clinic, Moorselbaan 164, 9300 Aalst, Belgium (E-mail: fillip.casselman@olvz-aalst.be).

J Thorac Cardiovasc Surg 2004;128:773-5

$0022-5223 / \$ 30.00$

Copyright @ 2004 by The American Association for Thoracic Surgery doi:10.1016/j.jtcvs.2004.05.016

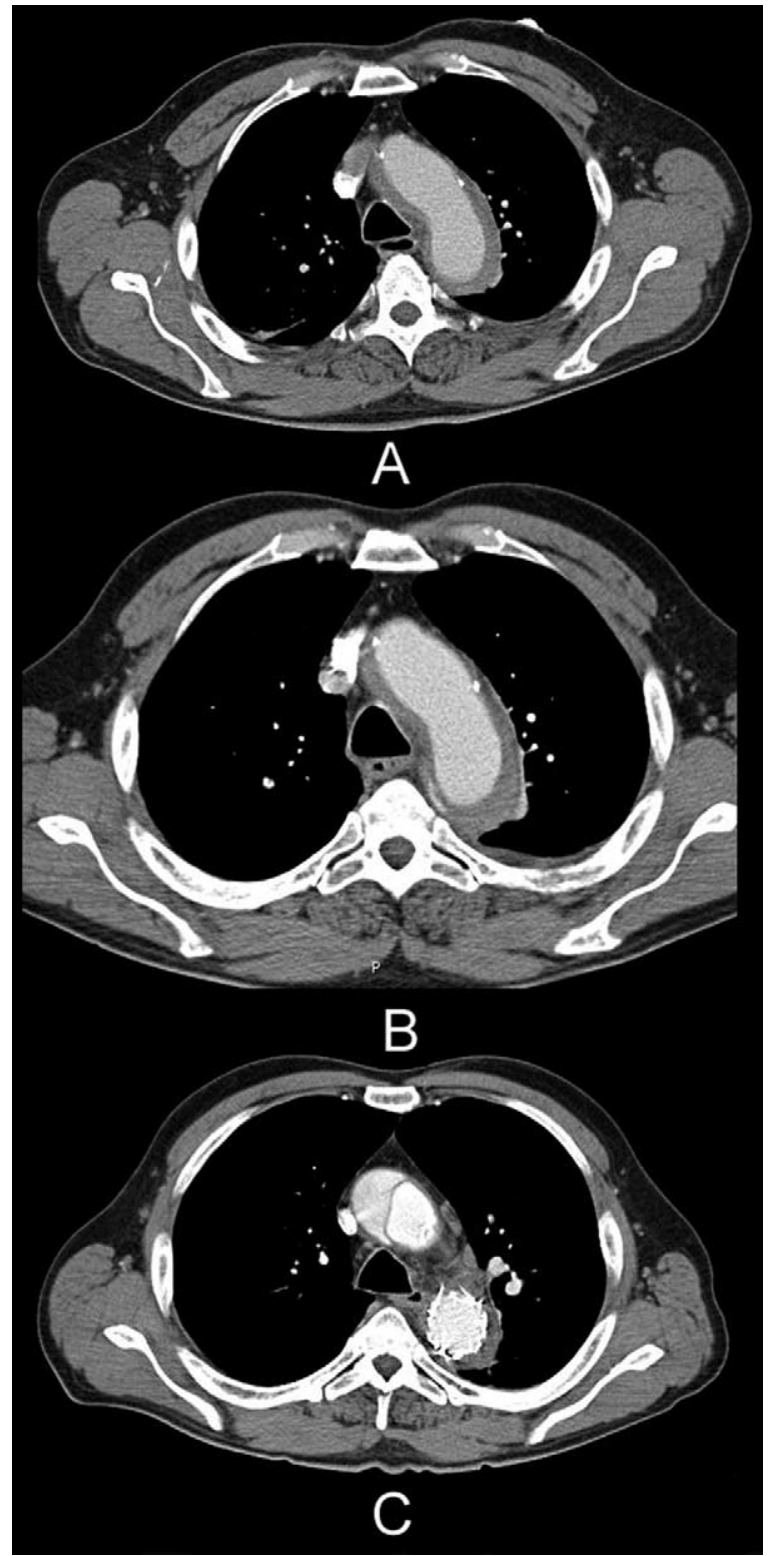

Figure 1. A, Thoracic CT scan at the first admission of the patient to the hospital. The IMH is in the ascending aorta, the arch, and the descending thoracic aorta. B, CT scan at the progression of the IMH in the descending thoracic aorta: a tear-like lesion appears in the proximal descending thoracic aorta. C, CT scan when type A dissection appears. 


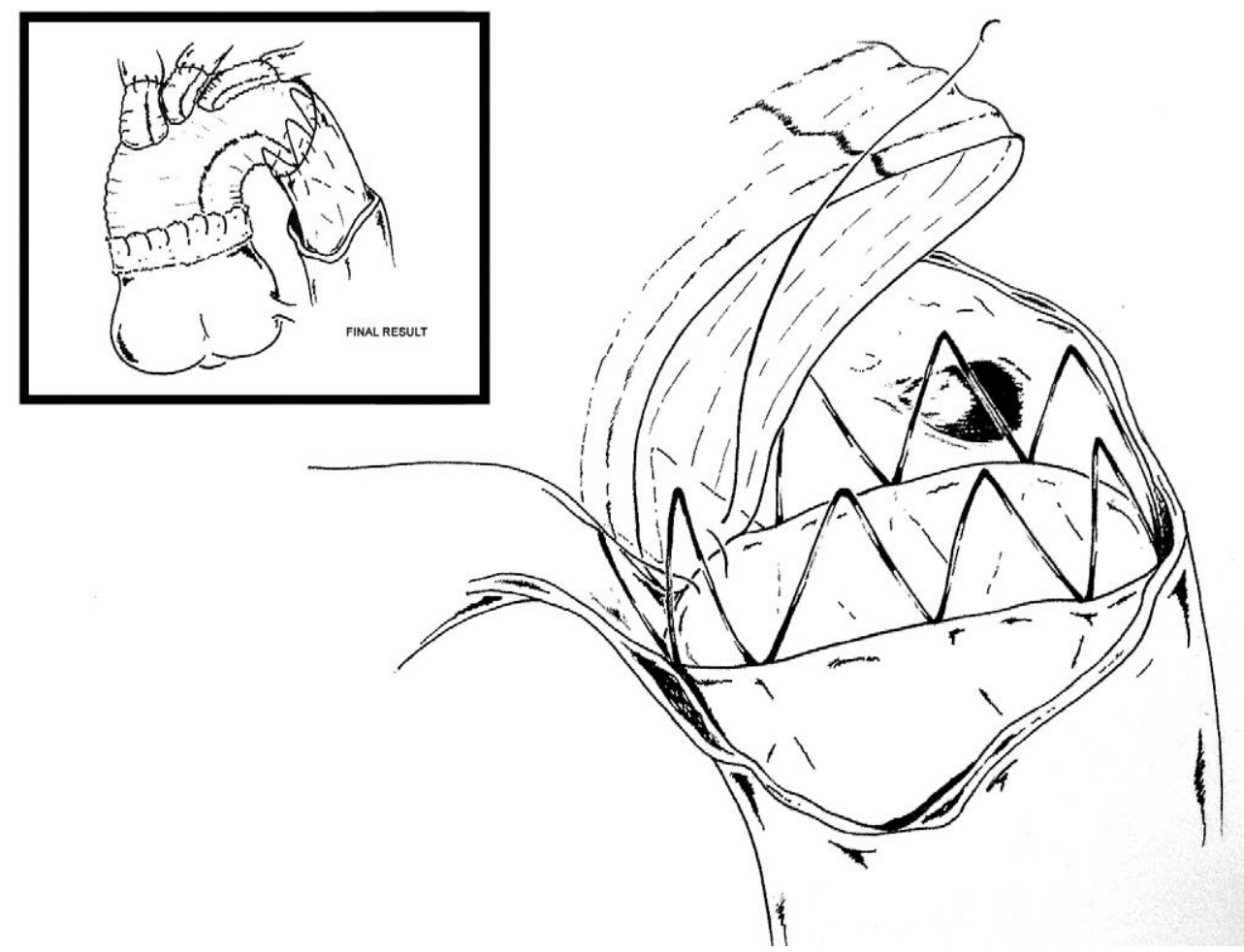

Figure 2. Technique of distal end-to-end anastomosis: the free bars are outside the suture line. The final result shows that it was necessary to leave the space between the left subclavian branch and the distal suture line longer than usual to avoid any interference with the free bars.

We performed a total arch replacement with separate supraaortic vessel reimplantation by antegrade selective cerebral perfusion. ${ }^{3}$ The distal anastomosis was performed with Prolene 4-0 sutures (Ethicon, Johnson \& Johnson Intl) in an end-to-end fashion between the new prosthetic graft (28-mm Sulzer Vascutek, Gelweave, 4 branches Plexus) and the endovascular stent graft, leaving the free bars of the stent outside (Figure 2). End-to-end subclavian artery reimplantation was performed, and the arch prosthesis was crossclamped; distal perfusion from the femoral artery was resumed. The proximal anastomosis was performed at the level of the sinotubular junction. With the heart beating, reimplantation of the left carotid artery and the brachiocephalic trunk, respectively, was completed, and the antegrade selective cerebral perfusion was stopped. No intraoperative or postoperative complications occurred.

\section{Discussion}

IMH is a localized collection of blood in the media of the aorta. The current trend for management is to treat this kind of lesion as a classic aortic dissection. ${ }^{2}$ Other authors ${ }^{1}$ have recently reported good results suggesting a more conservative approach. Initially, management of our case was conservative. When there were evident signs of progression, we decided to perform an endovascular stent implantation. The choice for the endovascular treatment was based on encouraging reported results, ${ }^{4}$ as well as our own experience with type B dissection. ${ }^{5}$ We supposed that by closing the only clear tear in the descending thoracic aorta, we could solve the problem. This strategy was found to be inadequate because we observed the evolution of the lesion to type A dissection in less than 1 month.

The main dilemma in the second operation was that the patient needed a total arch replacement with a stent graft in the proximal descending aorta. We were obliged to substitute the entire aortic arch because of the severe involvement of the supra-aortic vessels. We decided to perform the end-to-end distal anastomosis by directly connecting the new arch prosthesis to the endovascular graft, taking deep bites also in the surrounding aortic wall for the sutures reinforcement. We did not cut the free bars of the endovascular stent graft because we were afraid to impair the integrity of the stent itself. Looking at the final result, we believe that the technique we have used in this case report is feasible and provides satisfactory early results: it allows an absolutely hemostatic suture and a complete correction of the disease of the thoracic aorta, with its total replacement from the sinotubular junction until the proximal part of the descending thoracic aorta.

However, some doubt still remains regarding the management of this patient at the initial presentation. A type A intramural hematoma was the primary lesion, and what we experienced in this case report suggests that a more aggressive approach, as other authors report, ${ }^{2}$ could be justified. Stent graft replacement in this particular patient could not prevent an evolution toward a classical type A aortic dissection. 


\section{References}

1. Moizumi Y, Komatsu T, Motoyoshi N, Tabayashi K. Clinical features and long-term outcome of type A and type B intramural hematoma of the aorta. J Thorac Cardiovasc Surg. 2004;127:421-7.

2. Tittle SL, Lynch RJ, Cole PE, Singh HS, Rizzo JA, Kopf GS, et al. Midterm follow up of penetrating ulcer and intramural hematoma of the aorta. J Thorac Cardiovasc Surg. 2002;123:1051-9.

3. Di Bartolomeo R, Di Eusanio M, Pacini D, Pagliaro M, Savini C,
Nocchi A, et al. Antegrade Selective cerebral perfusion during surgery of the thoracic aorta: risk analysis. Eur J Cardiothorac Surg. 2001;19: 765-70.

4. Nienaber CA, Fattori R, Lund G, Dieckmann C, Wolf W, von Kodolitsch Y, et al. Nonsurgical reconstruction of thoracic aortic dissection by stent graft placement. N Engl J Med. 1999;340:153945.

5. Lambrechts D, Casselman F, Schroeyers P, De Geest R, D'Haenens P, Degrieck I. Endovascular treatment of the descending thoracic aorta. Eur J Vasc Endovasc Surg. 2003;26:437-44. 